\title{
Continuous and intermittent sibutramine were equally effective at 44 weeks for reducing weight in obesity
}

Wirth A, Krause J. Long-term weight loss with sibutramine: a randomized controlled trial. JAMA 2001 Sep

19;286:1331-9.

\section{QUESTION: In obese people, is sibutramine effective for reducing weight?}

Design

Randomised (allocation concealed*), blinded (investigators and patients),* placebo controlled trial with 44 weeks of follow up after randomisation.

\section{Setting}

108 private practices and 3 hospital outpatient departments in Germany.

\section{Patients}

1001 patients who were 18 to 65 years of age (mean age 43 y, $77 \%$ women), had a body mass index (BMI) of 30 to $40 \mathrm{~kg} / \mathrm{m}^{2}$, and had $\geqslant 1$ previous unsuccessful attempt at losing weight by using dietary measures. Exclusion criteria were serious cardiovascular or metabolic diseases; history of drug or alcohol abuse; need for antidepressants, $\beta$-blockers, or any drugs influencing body weight; or inadequate contraception in women of childbearing age. $79 \%$ of patients completed the study; all patients were included in the analysis.

\section{Intervention}

Patients who responded (ie, weight loss of $\geqslant 2 \%$ or $\geqslant 2$ $\mathrm{kg}$ ) to sibutramine $15 \mathrm{mg}$ /day, during a 4 week run-in period, were allocated to 1 of 3 groups for 44 more weeks: continuous sibutramine $15 \mathrm{mg} /$ day $(\mathrm{n}=405)$; intermittent sibutramine $15 \mathrm{mg}$ /day during weeks 1-12, $19-30$, and $37-48(n=395)$; or placebo $(n=201)$.

\section{Main outcome measure}

Weight loss.

\section{Main results}

Analysis was by intention to treat. Mean weight loss at 44 weeks after randomisation was $3.8 \mathrm{~kg}(95 \%$ CI 3.2 to 4.4$)$ for continuous sibutramine and $3.3 \mathrm{~kg}$ (CI 2.7 to 4.0) for intermittent sibutramine; patients in the placebo group gained weight (mean $0.2 \mathrm{~kg}$, CI -0.6 to 0.9$)(\mathrm{p}<0.001$ for the difference between each treatment group and placebo). More patients in each of the treatment groups than in the placebo group lost 5\% and 10\% of their baseline weight ( $\mathrm{p}<0.001$ for all comparisons) (table). The 2 treatment groups did not differ for weight loss.

Dr A Wirth

Teutoburger-Wald-Klinik

Germany.

wirthbr@t-online.de.

\section{Conclusion}

In obese people, continuous or intermittent sibutramine were equally effective for reducing weight.

*See glossary.

\section{COMMENTARY}

Given the unabating rise in obesity prevalence, our treatment armamentarium clearly leaves something to be desired. Pharmacological choices are limited and have a questionable safety record, and none is impressively effective. The study by Wirth and Krause of sibutramine, an anorexigenic noradrenaline and serotonin reuptake blocker available since 1998, is of some interest to clinicians who are challenged by the prospect of helping their obese patients. The interest in this study is not so much because of its redundant finding that sibutramine has a modest salutary effect over placebo for initial weight loss, but because it showed that intermittent treatment (about $75 \%$ of the time on, $25 \%$ of the time off) was about as effective as continuous treatment. One 36 week controlled trial of an older agent, phentermine, also found this effect when alternating 4 week blocks of time on and off the drug. ${ }^{1}$

Because most patients I see take antiobesity medications in an intermittent fashion anyway, this finding is reassuring. Intermittent use is also probably safer than the never ending treatment of obesity that is often advocated but has yet to be shown effective in studies of $>2$ years. Whether any antiobesity agent that acts systemically will prove entirely safe in the long term is, unfortunately, unknown. Sibutramine has certain known problems, notably its propensity to raise blood pressure and pulse (in part undermining one of the main reasons to use it in the first place). Nonetheless, sibutramine has some proven efficacy, and we should not hold antiobesity drugs to a higher standard than drugs used to control hypertension or diabetes. If only we had as many good choices and combinations for obesity as we do for hypertension and diabetes: to begin with, we would not need to treat nearly as many patients for the latter two.

Given the high stakes, we have no choice but to keep trying to find effective and safe pharmacological and other treatments for obesity. Basic science and pharmacology will no doubt uncover further options as the years unfold. Lawrence J Cheskin, MD Johns Hopkins Bloomberg School of Public Health Baltimore, Maryland, USA

1 Munro JF, MacCuish AC, Wilson EM, et al. Comparison of continuous and intermittent anorectic therapy in obesity. Br Med J 1968;1:352-4. 